\title{
Power Injection System for Grid Connected Photovoltaic Generation Systems based on two Collaborative Voltage Source Inverters
}

\author{
Enrique Romero-Cadaval, Member, IEEE, María I. Milanés Montero, Member, IEEE, Eva González \\ Romera, Member, IEEE, and Fermín Barrero González, Member, IEEE
}

\begin{abstract}
This paper presents a new topology for the power injection system that is based on the parallel association of two voltage source inverters: one is operated using a quasi-square voltage waveform strategy and the other operates with a PWM based strategy. The aim of this topology is that the quasi-square inverter injects the power from the photovoltaic generation system and the PWM inverter controls the current quality. The proposal optimizes the system design, permitting reduction of system losses and an increase of the energy injected into the grid.
\end{abstract}

\section{INTRODUCTION.}

The number of photovoltaic generation systems (PVGS) is increasing rapidly in Spain, due principally to Spanish government subsidies.

The energy produced by a PVGS must be injected into the electric grid, according to pre-established quality and reliability specifications, without affecting grid's normal operation.

This PVGS presents a power injection system (PIS) that has the function of injecting the power produced by the photovoltaic cell groups, converting the energy from the original DC form to the final AC form with the desired electrical characteristics. The part of the PIS that carries out this conversion is the inverter [1,2]. Usually, Pulse Width Modulation (PWM) based inverters [1,3] or multilevel topology inverters are used $[1,4]$.

In this paper a new topology for the PIS is presented based on the parallel association of two voltage source inverters (VSI): one is operated using a quasi-square voltage waveform strategy (quasi-square waveform inverter, QSWI) and the other operates with a PWM based strategy (high-switching-frequency inverter, HSFI). The general purpose of the QSWI is to inject the power generated by the PVGS; and that of the HSFI is to be responsible for controlling the quality of the current injected into the grid.

Manuscript received November 8, 2007. Accepted for publication Jun 16, 2008. This work was supported in part by the Spanish Ministry of Science and Education (MEC) under Grant ENE2006-10806.

Copyright (C) 2007 IEEE. Personal use of this material is permitted. However, permission to use this material for any other purposes must be obtained from the IEEE by sending a request to pubs-permissions@ieee.org

The authors are with the Power Electrical and Electronics Research Group of the University of the University of Extremadura. School of Industrial Engineering. Avda. de Elvas, s/n. Badajoz. Spain (eromero@unex.es)

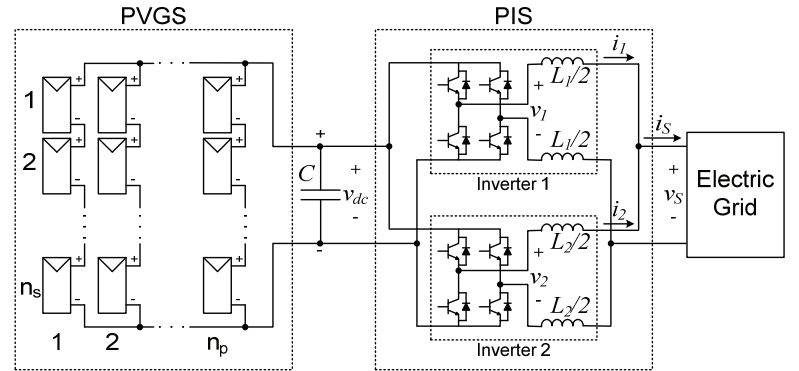

Fig. 1 Proposed system scheme.

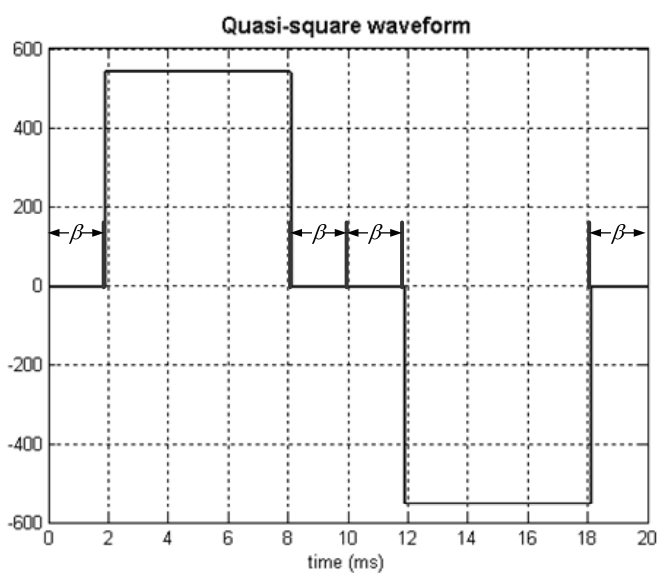

Fig. 2 Quasy-square waveform.

\section{PIS DESCRIPTION}

The grid connected PVGS scheme analyzed is shown in Fig. 1.

A direct connection to the inverters without a previous DC/DC converter has been chosen.

The upper inverter in the figure (inverter 1) is the QSWI and the lower inverter (inverter 2), the HSFI.

\section{A. QSWI: Quasi-square wave inverter}

The objective of the inverter is to inject the energy from the PVGS into the grid. In order to achieve this, controlling the fundamental component of the inverter voltage is sufficient, under the assumption that the voltage does not present harmonics. 

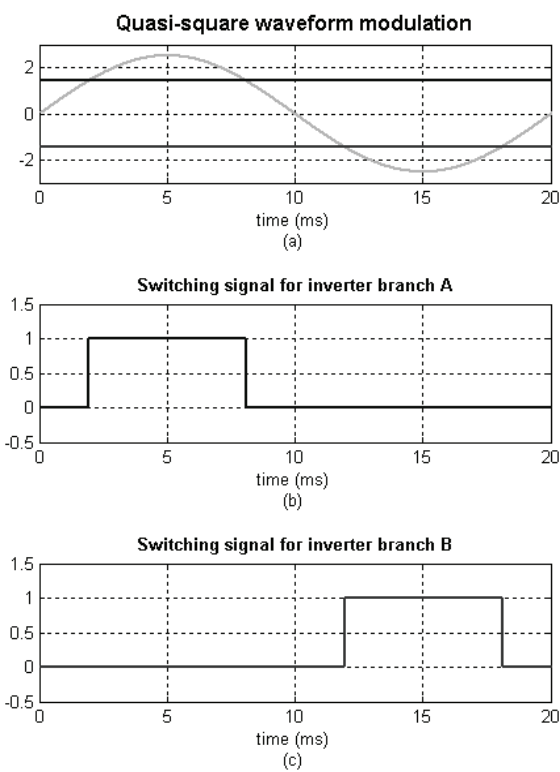

Fig. 3 Quasi-square waveform modulation for obtaining the two branches switching signals: (a) carrier waveform (sinusoidal wave) and modulator waveforms, (b) switching signal for branch A, (c) switching signal for branch $\mathrm{B}$.

The power generated by the PVGS, with negligible inverter losses, is equal to the power injected into the electric grid:

$$
P_{S}=V_{S} I_{S, 1} \cos \varphi \text {. }
$$

where $V_{S}$ is the RMS supply voltage, $I_{S, 1}$ the RMS fundamental supply current component, and $\varphi$ is the displacement angle between voltage and fundamental current component.

Examining the proposed system topology (Fig. 1), one has that the inverter 1 fundamental voltage component is

$$
\vec{V}_{1}=\vec{V}_{S}+j L_{1} \omega \vec{I}_{1,1}=\vec{V}_{S}+j L_{1} \omega \vec{I}_{S, 1} .
$$

where $I_{l, 1}$ is the fundamental current component of inverter 1 that ideally should be equal to $I_{S, 1}$.

The RMS value of the fundamental component of the quasi-square inverter voltage waveform (Fig. 2) is

$$
V_{1,1}=0.9 V_{P V G S} \cos \beta \text {, }
$$

where $\beta$ is half the angle (in radians) when the quasisquare waveform is zero. This angle can be expressed as

$$
\beta=\omega t_{0},
$$

where $\omega$ is the grid voltage pulsation and $t_{0}$ is half the time interval that the QSWI voltage is zero.

The control system of this inverter not only must inject the energy into the electric grid, but also guarantee that the displacement power factor is equal to unity. This is achieved when the current injected by the inverter is

$$
i_{1}(t)=I_{S, 1} u_{s, d}(t) \text {, }
$$

where $u_{s, d}(t)$ is a sinusoidal wave with unity RMS value, and with the same frequency and phase as the supply voltage.

Equation (2) can be expressed as

$$
\vec{V}_{1}=\vec{V}_{S}+L_{1} \omega I_{S, 1}\left(j \frac{\vec{V}_{S}}{V_{S}}\right)
$$

and taking into account (3), the control system must guarantee that

$$
\beta=\arccos \left(\frac{\sqrt{V_{S}^{2}+\left(L_{1} \omega I_{S, 1}\right)^{2}}}{0.9 V_{P V G S}}\right) .
$$

This value is obtained with a modulation process at the fundamental frequency using a sinusoidal carrier waveform constructed from (6):

$$
u_{p}(t)=u_{S, d}(t)+\frac{L_{1} \omega I_{S, 1}}{V_{S}} u_{S, q}(t) \text {. }
$$

This carrier waveform guarantees that the quasi-square waveform maintains the phase needed to generate the fundamental supply current component in phase with the grid voltage.

Two constant waveforms are used as modulators: one for each branch of the single-phase inverter (as shown in Fig. 3). In order to guarantee the RMS value of the fundamental supply current component, the modulator waves are

$$
U_{m, A}(t)=-U_{m, B}(t)=u_{p}\left(\frac{\beta}{\omega}\right)=\sqrt{1+\left(\frac{L_{1} \omega I_{S, 1}}{V_{S}}\right)^{2}} \sin \beta .
$$

\section{B. HSFI: High-switching-frequency inverter}

This inverter must control the quality of the current injected into the grid by adding the needed current $\left(i_{2}\right)$ to the current injected by the QSWI $\left(i_{1}\right)$.

The inverter control is implemented using a synchronous hysteresis band $[5,6,7]$ with a high switching frequency (usually between 10 and $20 \mathrm{kHz}$ ). The difference between the sinusoidal current reference $\left(i_{S, \text { ref }}\right.$ obtained from (1) to (5)) and the current effectively injected into the grid $\left(i_{S}\right.$, measured from the real system and equal to the sum of the currents injected from the two inverters) is used as error signal. The operation of the hysteresis band control must eliminate the existing error.

\section{Passive element selection}

The QSWI inductance value $\left(L_{1}\right)$ must be selected to permit the injection of the maximum power that the PVGS can generate (which depends on the irradiance and temperature conditions).

The power injected into the grid from the PVGS (neglecting the PIS losses) is

$$
P_{S}=V_{S} I_{S, 1}=P_{P V G S} \text {, }
$$

as the current is in phase with the grid voltage.

The RMS fundamental current component injected by the QSWI $\left(I_{1}\right)$ can be determined from (2):

$$
I_{1}=\frac{\sqrt{V_{1}^{2}-V_{S}^{2}}}{L_{1} \omega} \text {. }
$$

From (10) and (11) one obtains

$$
L_{1}=\frac{V_{S}}{\omega P_{P V G S}} \sqrt{V_{1}^{2}-V_{S}^{2}} \text {. }
$$

It can be deduced from the last expression that the DC inverter input voltage must be at least 


$$
V_{d c}=\frac{V_{S}}{0.9}
$$

to guarantee that values for the inductance $L_{1}$ exist.

This DC voltage value does not permit good system operation, because the quasi-square waveform degenerates to a square waveform. Using a higher DC voltage as design value for the usual operation conditions (irradiance and temperature) is recommended. A value of $\pi / 6 \mathrm{rad}\left(30^{\circ}\right)$ for the characteristic quasi-square waveform angle $(\beta$, equation (7)) eliminates the triple harmonics from the voltage (and injected current) spectrum. Therefore this consideration in design guarantees that a control operation margin will exist in changing irradiance and temperature situations. The inductance with the proposed DC voltage is given by

$$
L_{1}=\frac{V_{S}}{\omega P_{P V G S}} \sqrt{\left(0.9 V_{d c} \cos \frac{\pi}{6}\right)^{2}-V_{S}^{2}},
$$

so, for valid values to exist, it must satisfy

$$
V_{d c}>0.78 V_{S} \text {. }
$$

The HSFI inductor $\left(L_{2}\right)$ must be chosen as high as possible (thus achieving maximum filtering) but taking into account that this value must permit the needed current derivatives in order to build the total supply current with the desired quality. The quality must be guaranteed even in the worst case (maximum supply voltage for positive derivatives and minimum for negative derivatives). For a given current derivative or slope, $i_{2, \text { slope }}$, one has

$$
L_{2}=\frac{V_{d c}-\sqrt{2} V_{S}}{i_{2, \text { slope }}} \text {. }
$$
that

To produce valid inductance values, one must have

$$
V_{d c}>1.41 V_{S} \text {. }
$$

This condition is more restrictive for the DC voltage than the one imposed by (15).

The capacitor between the PVGS and the PIS $(C)$ must absorb the active power fluctuations (that always exist in a single-phase system). Therefore it achieves constant power extracted from the PVGS, by keeping the DC voltage at the output terminal of the PVGS constant under these power fluctuations.

As the supply current is in phase with the grid voltage, and assuming it to be sinusoidal, the instantaneous power becomes

$$
p_{S}(t)=v_{S}(t) i_{S}(t)=2 V_{S} I_{S} \sin ^{2} \omega t
$$

and the power fluctuations are due to the energy that is stored and discharged in the capacitor, so that the instantaneous power associated with the capacitor is

$$
\begin{aligned}
p_{C}(t) & =p_{S}(t)-P_{P V G S}=p_{S}(t)-P_{S}= \\
& =2 V_{S} I_{S} \sin ^{2} \omega t-V_{S} I_{S}=V_{S} I_{S}(-\cos 2 \omega t) .
\end{aligned}
$$

The energy discharged from the capacitor in one quarter of the fundamental period (which will be equal to the energy stored in the next quarter) is

$$
\begin{aligned}
e_{C}(t) & =\int_{T / 8}^{3 T / 8} p_{C}(t) d t=V_{S} I_{S} \int_{T / 8}^{3 T / 8}(-\cos (2 \omega t)) d t= \\
& =V_{S} I_{S} \frac{1}{2 \omega}[\sin (2 \omega t)]_{3 T / 8}^{T / 8}=\frac{V_{S} I_{S}}{\omega}=\frac{P_{P V G S}}{\omega} .
\end{aligned}
$$

This discharged energy produces a capacitor voltage decrease:

$$
e_{C}(t)=\frac{1}{2} C\left(V_{C \max }^{2}-V_{C \min }^{2}\right) \text {. }
$$

If the voltage decrease is small, the above equation can be written as

$$
e_{C}(t)=\frac{1}{2} C\left(\left(V_{d c}+\widetilde{v}_{C}\right)^{2}-\left(V_{d c}-\widetilde{v}_{C}\right)^{2}\right)=2 C V_{d c} \widetilde{v}_{C}
$$

where $\tilde{v}_{C}$ is the capacitor voltage fluctuation.

To guarantee that the relative voltage fluctuations are lower than a pre-established value, they must satisfy

$$
\frac{\widetilde{v}_{C}}{V_{d c}}=\frac{e_{C}(t)}{2 C V_{d c}^{2}}=\frac{P_{P V G S}}{2 C \omega V_{d c}^{2}} \leq \varepsilon \Rightarrow C \geq \frac{P_{P V G S}}{2 \varepsilon \omega V_{d c}^{2}},
$$

where $\varepsilon$ is the maximum relative value of the DC voltage ripple.

\section{CONTROL SYSTEM}

The PIS control can be divided into the blocks shown in the schematic diagram of Fig. 4.

\section{A. Maximum Power Point Tracking (MPPT) block}

The objective of this block is to set and to maintain the PVGS at its maximum power point (MPP). When the PVGS is working at this point, one hast that

$$
\frac{d P_{P V G S}}{d V_{p v}}=0 \text {. }
$$

The MPPT scheme is shown in Fig. 5. In the proposed system, this condition is achieved by considering the power derivative as the error input of a proportionalintegral (PI) controller. In this way if the PI controller is well-designed, the power derivative will become zero in the steady state and the MPP will be tracked.

A saturation function has been included to prevent the improper operation of the integral part of the controller during start-up transients. A low-pass filter is included to eliminate the components in the power derivative due to the switching frequency.

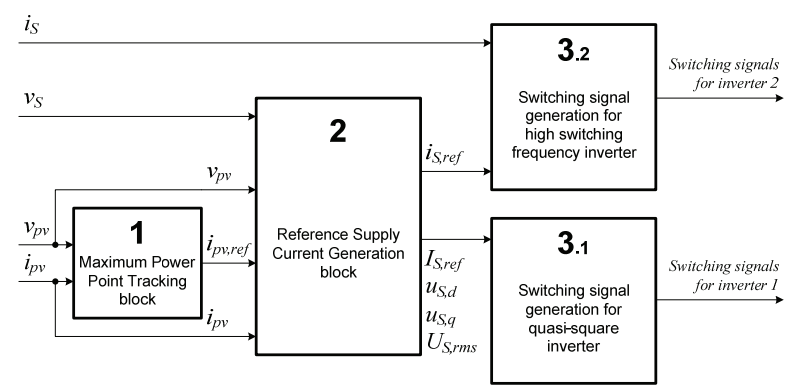

Fig. 4 PIS control system scheme. 

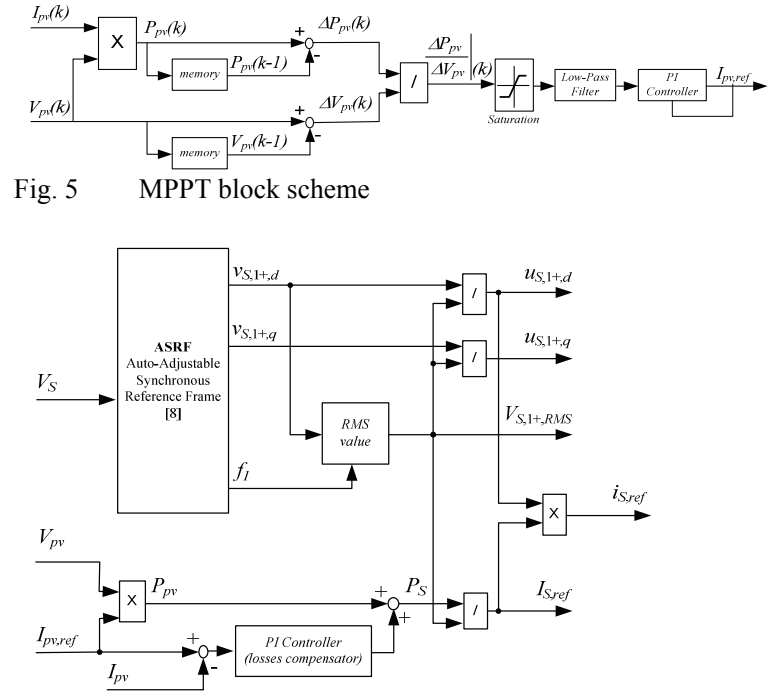

Fig. 6 RSCG block scheme.

\section{B. Reference Supply Current Generation (RSCG) block}

This is the principal block of the proposed control system, because it guarantees that the current extracted from the PVGS is the desired one and so the MPP is tracked.

The RMS value of the fundamental current component that must be injected into the grid is determined by neglecting the PIS losses:

$$
I_{S, r e f}=\frac{V_{P V} I_{P V, r e f}}{V_{S}} \text {. }
$$

This reference current value is tuned by the output of an additional PI whose input is the error between the reference current that must be extracted from the PVGS (determined by the MPPT block) and the actual one (measured from the system). The aim of this tuning is to compensate the system losses that have not been considered in (25).

The RSCG block contains a synchronization module [8] that generates two sinusoidal signals with unity RMS value, which are in phase (the first one) and in quadrature (the second one) with the fundamental grid voltage component, and an RMS grid voltage fundamental component calculation module $[9,10,11]$.

As a result the reference supply current is a sinusoidal wave $\left(i_{S, r e f}\right)$ in phase with the grid voltage, and its RMS value is equal to that given by (25).

The resulting diagram for this block is shown in Fig. 6.

\section{Inverter Switching Signal Generation block}

This block implements the collaboration between the two inverters and their principle of operation was described in section 2. Figures 7 and 8 show the schematic diagram for each inverter.

In Fig. 7 the function block "Fen" implements (9), and the function block "Fcn1" is used to avoid values greater than 1 for the arc cosine function of this equation.

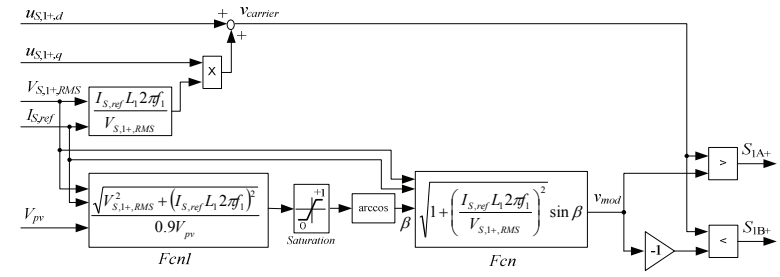

Fig. 7 Switching signal generation for inverter 1 .

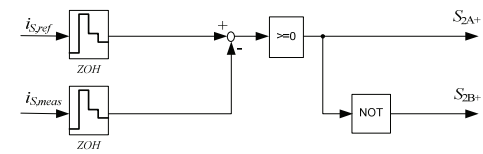

Fig. 8 Switching signal generation for inverter 2.

The QSWI is operated in a quasi-open-loop obtaining the value of $\beta$ from the reference supply current (determined in part B), not its measured value.

The HSFI switching signals are generated based on the error existing between the reference supply current and the measured one, by using a hysteresis band that compares the error with zero for a fixed sample period (Fig. 8).

\section{PIS EVALUATION THROUGH SIMULATION}

The control system evaluation is described out in this section using the model in Fig. 9, showing how the PIS is able to set and maintain the PVGS at its MPP even when changing the operation irradiance or temperature.

A model for the PVGS that permits on-line irradiance and temperature changes is used [12]. The principal characteristics of the PVGS and PIS are summarized in Table 1 and 2 .

The simulated PVGS used for PIS evaluation has 16 series connected photovoltaic cells (Shell SP150-P). It produces a maximum power point voltage of about $550 \mathrm{~V}$ for the reference operation conditions of irradiance, 1000 $\mathrm{W} / \mathrm{m}^{2}$, and temperature, $25^{\circ} \mathrm{C}$, that satisfies the condition imposed in (17). The main magnitudes of the system when starting-up and when changing the irradiance conditions following the profile of Fig. 10 are shown in Fig. 11. The irradiance profile was selected to evaluate the PIS (to simulate the decreasing irradiance level when the sun is shadowed by a cloud). The irradiance changes presented in this profile are sharper than usual, so the PIS is evaluated in a harsher than normal conditions.

Table 2 shows the PIS parameters values used in the simulation test for a supply voltage of $220 \mathrm{~V}-50 \mathrm{~Hz}$.

\section{PIS OPERATION ANALYSIS}

A detail of the most representative waveforms for evaluating the PIS (near $\mathrm{t}=1 \mathrm{~s}$, after the system has reached its steady state) is shown in Fig. 12. The spectrum analyses of the main current waveforms are shown in Fig. 13 (component spectrum in real magnitudes) and Fig. 14 (individual harmonic distortion). 
Table 1. PVGS Characteristics

\begin{tabular}{lc}
\hline Parameter & Value \\
\hline Number of series connected cells & 16 \\
\hline Number of parallel connected cells & 1 \\
\hline Photovoltaic cell reference & SHELL SP150-P \\
\hline Short-circuit current $\left(25^{\circ} \mathrm{C}, 1000 \mathrm{~W} / \mathrm{m}^{2}\right)$ & $4.8 \mathrm{~A}$ \\
\hline Open-circuit voltage $\left(25^{\circ} \mathrm{C}, 1000 \mathrm{~W} / \mathrm{m}^{2}\right)$ & $43.4 \mathrm{~V}$ \\
\hline MPP current $\left(25^{\circ} \mathrm{C}, 1000 \mathrm{~W} / \mathrm{m}^{2}\right)$ & $4.4 \mathrm{~A}$ \\
\hline MPP voltage $\left(25^{\circ} \mathrm{C}, 1000 \mathrm{~W} / \mathrm{m}^{2}\right)$ & $34 \mathrm{~V}$ \\
\hline $\begin{array}{l}\text { Open circuit voltage variation coefficient for } \\
\text { irradiance changes }\end{array}$ & $0.85 \mathrm{~V} /\left(\mathrm{W} / \mathrm{m}^{2}\right)$ \\
\hline $\begin{array}{l}\text { Open circuit voltage variation coefficient for } \\
\text { temperature changes }\end{array}$ & $0.12 \mathrm{~V} /{ }^{\circ} \mathrm{C}$ \\
\hline
\end{tabular}

Table 2. PIS Parameteres

\begin{tabular}{lc}
\hline Parameter & Value \\
\hline Filter inductance L1 & $50 \mathrm{mH} \times 2$ \\
\hline Filter inductance L2 & $25 \mathrm{mH} \times 2$ \\
\hline Switching frequency & $20 \mathrm{kHz}$ \\
\hline
\end{tabular}

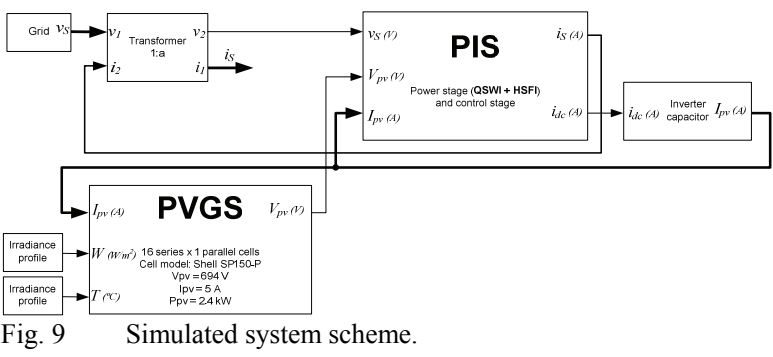

The QSWI inverter generates a current that injects the power extracted from the PVGS (that matches the maximum power as shown in the previous section) into the grid, but the quality of this current is low (THD $>5 \%$ and some $\mathrm{IHD}_{\mathrm{h}}$ above 3\%, Fig. 14 (b)).

The HSFI performance improves the total injected current quality reaching a $\mathrm{THD}<5 \%$ and keeping all the $\mathrm{IHD}_{\mathrm{h}}$ below $2 \%$ (Fig. $14(\mathrm{~d})$ ).

Similar analysis has been done for the interval 1.94 to $2 \mathrm{~s}$. The irradiance level is $750 \mathrm{~W} / \mathrm{m} 2$ and the angle $\beta$ of the QSWI is nearly $45^{\circ}$. Then the THD becomes $12.5 \%$ for QSWI current, $13.4 \%$ for HSFI and 4.9\% for supply current (Fig. 15).

The main advantage of the proposed system is the inverter loss decrease, because the QSWI has low losses which are due principally to conduction. The switching losses are small because the switching frequency matches the grid frequency, near $50 \mathrm{~Hz}$. The conduction losses could be even further reduced if a low ON- voltage semiconductor is selected, since no high speed switching semiconductors are needed for this inverter.

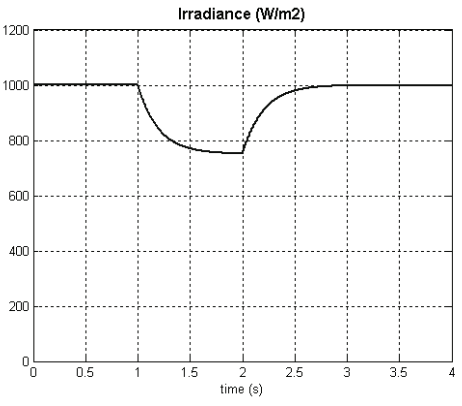

Fig. 10 Irradiance profile used for the simulation test.

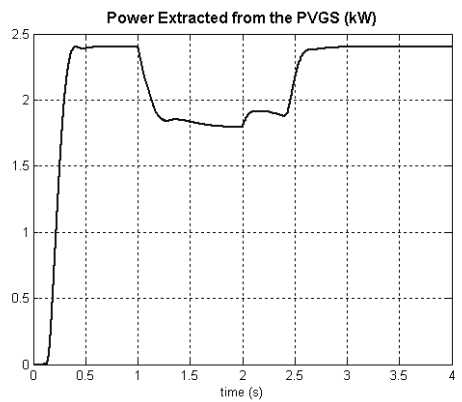

(a)

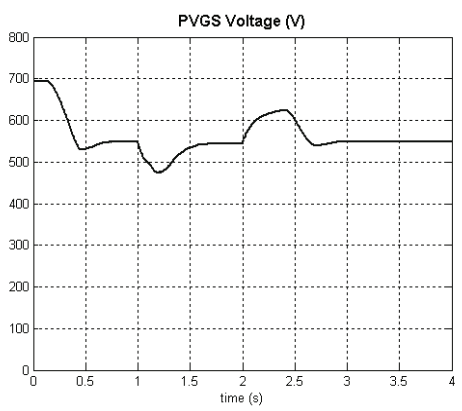

(b)

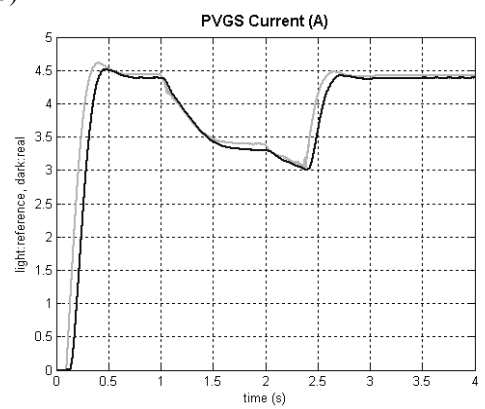

(c)

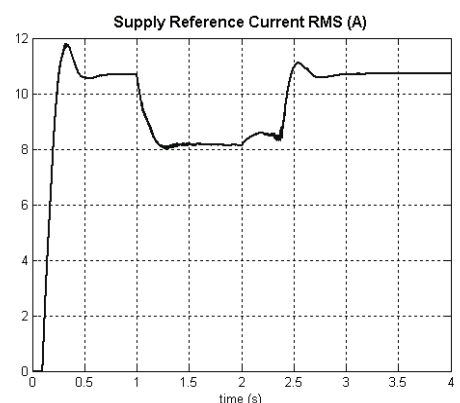

(d)

Fig. 11 Principal magnitude waveforms in the start-up process and with changing irradiance. 


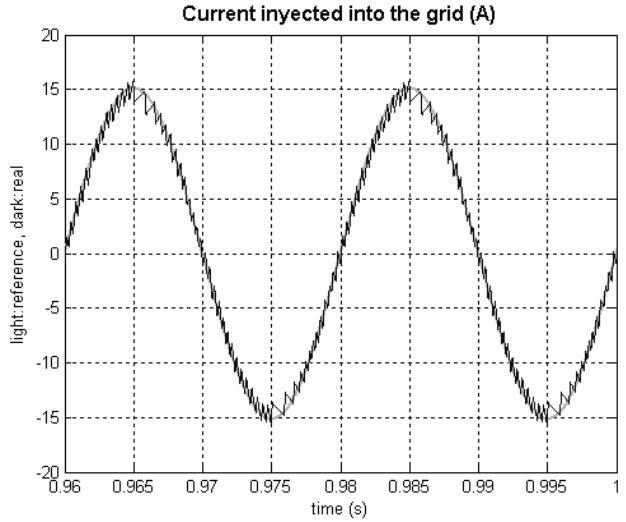

(a)

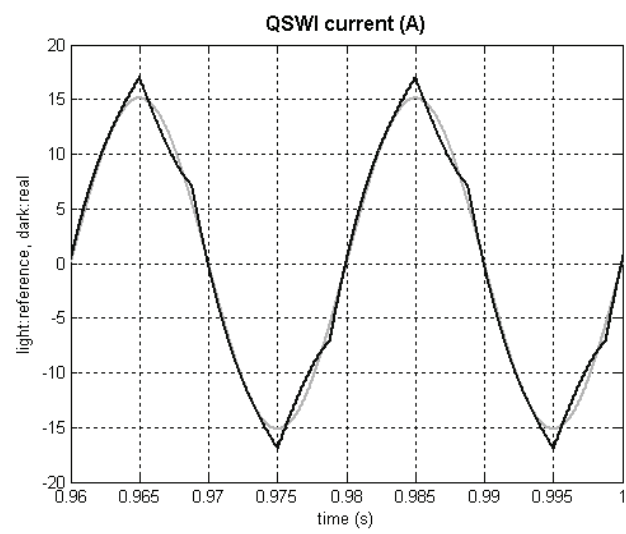

(b)

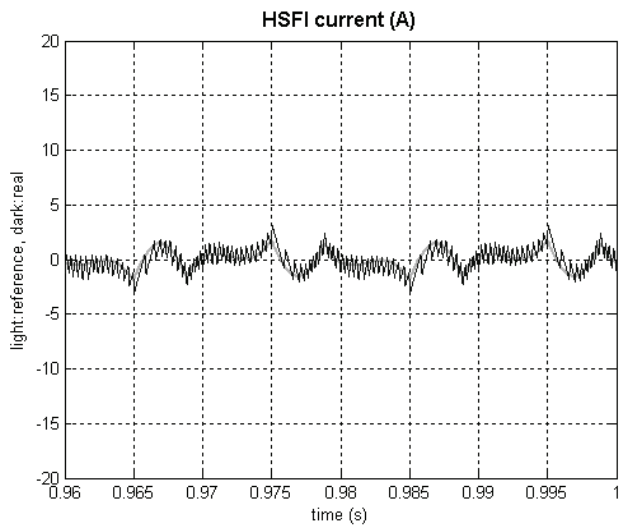

(c)

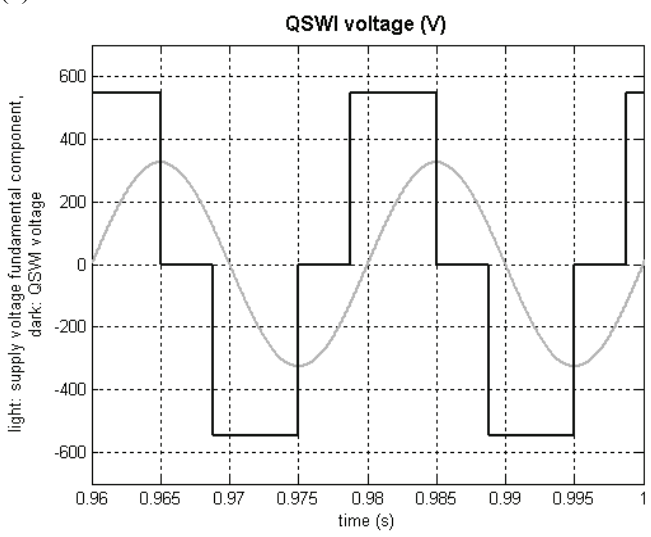

(d)

Fig. 12 Detail (near to $t=1 \mathrm{~s}$, after the system has reached its steady state) of the most representative waveforms for the PIS analysis: (a) total current injected into the grid (sum of the two inverter currents), (b) current generated by the QSWI, (c) current generated by the HSFI, and (d) voltage waveform at the terminal of the QSWI , and grid voltage.
But also losses in the HSFI (principally due to the switching losses) decrease notably, because the current levels for this inverter are lower than those produced if it was working alone (without the QSWI cooperation). This can be observed in Fig. 12 (c), where the maximum instantaneous current value is lower than $3 \mathrm{~A}$, a value that is significantly lower than the maximum value of $15 \mathrm{~A}$ for the total injected current, Fig. 12 (a). If one assumes that the switching losses are proportional to the maximum instantaneous current value, these losses will be reduced to approximately $20 \%$. Therefore the high switching semiconductors used in this inverter will have a current ratio of about five times lower than the semiconductor used in a conventional PWM inverter for the same task. The reduction in losses allows one to use a smaller aluminium radiator.

Furthermore, the QSWI inductor can be built with a conventional core coil designed for a working frequency of $50 \mathrm{~Hz}$ (ferromagnetic core and conventional cupper wire), and the HSFI inductor can be built with an air core coil with smaller section cupper wire (usually special cupper wires must be used due to the high switching frequency), because the RMS current value is smaller than if it operates alone. The total inductor losses will be lower:

- the electric losses in inductor of inverter 1 decrease because it has a lower resistance $\left(R_{l}\right)$ than if it had been built with air core coils (because far fewer turns of cupper wire are needed). Ferromagnetic losses will be small since the operation frequency is $50 \mathrm{~Hz}$.

- the electric losses in inductor of inverter 2 decrease too, because the RMS of the current that flows through it $\left(I_{2}\right)$ is reduced by five times.

Although the cost could seem to increase due to the more complex topology and control and to the higher number of semiconductors needed, others factor related to cost should be taken into account: decrease in losses and so decrease in the size of the aluminium radiator, possibility of using ferromagnetic core inductors for filtering the greater fraction of the current (this inductors are about $30 \%$ less expensive than air core inductors [14]), possibility of using slower semiconductors (so cheaper devices) for the greater current fraction, and using lower rating high frequency semiconductors (because they operate with a lower current fraction).

\section{EXPERIMENTAL RESULTS}

The proposed PIS has been tested with a laboratory prototype (Fig. 16)

HP-E4351B solar array simulator (supplying $70 \mathrm{~V}_{\mathrm{DC}}$ ) is connected to a four branches inverter (SEMIKRON CON.IGBT MULTIDIDACT 4GB) forming the power stage that injects the power into the grid $(220 \mathrm{~V} 50 \mathrm{~Hz})$ trough an autotransformer (1:20).

The principal prototype values are summarized in Table 3. The results are shown in Fig. 17 and 18. 


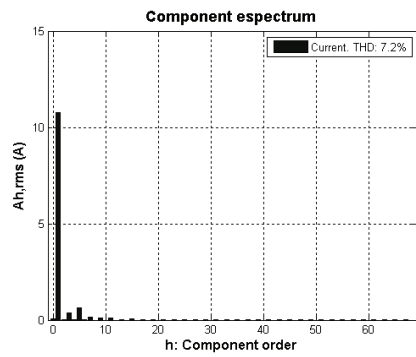

(a)

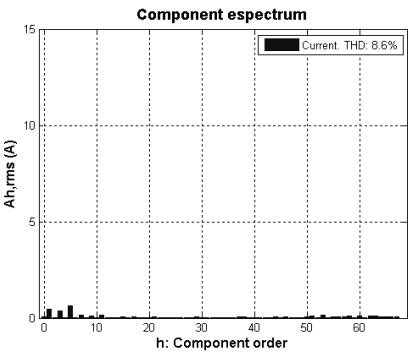

(b)

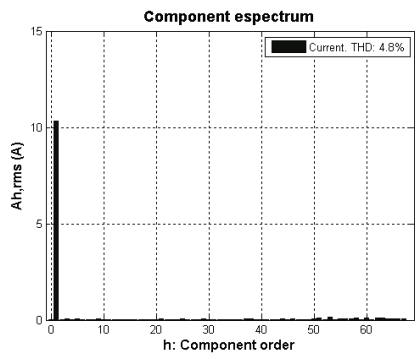

(c)

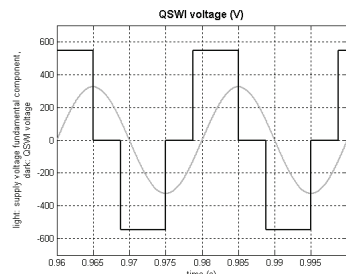

(a)

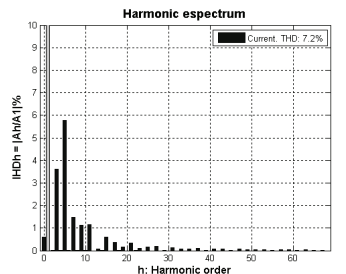

(b)

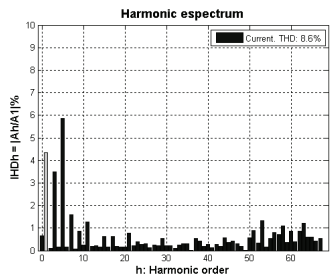

(c)

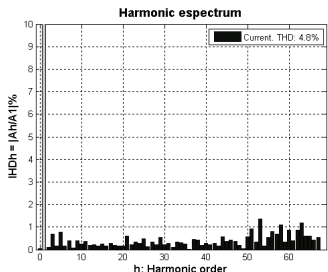

(d)

Fig. 14 Analysis for $\mathrm{t}=1 \mathrm{~s}$, irradiance $=1000 \mathrm{~W} / \mathrm{m}^{2}$. (a) Voltage waveform at the terminal of the QSWI, and grid voltage. Individual harmonic distortion ratio (taking as base value the fundamental component of the total injected current) for: (b) QSWI current, (c) HSFI current and (d) Total injected current (sum of the two inverters).

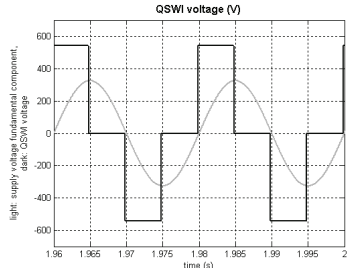

(a)

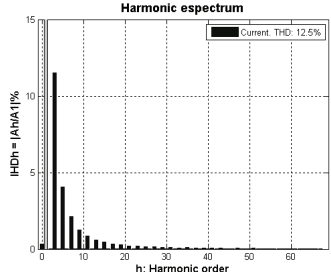

(b)

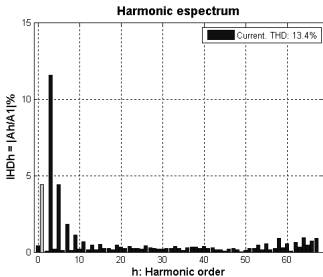

(c)

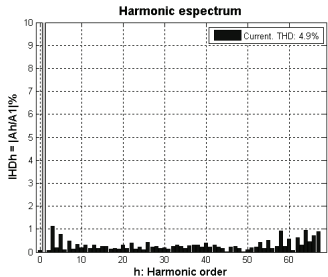

(d)

Fig. 15 Analysis for $\mathrm{t}=2 \mathrm{~s}$, irradiance $=750 \mathrm{~W} / \mathrm{m}^{2}$ : (a) Voltage waveform at the terminal of the QSWI, and grid voltage. Individual harmonic distortion ratio (taking as base value the fundamental component of the total injected current) for: (b) QSWI current, (c) HSFI current and (d) Total injected current (sum of the two inverters).

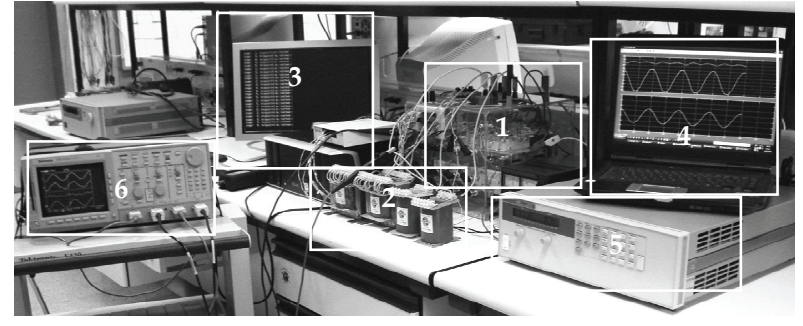

Fig. 16 General view of the PIS laboratory prototype: (1) four branches SEMICRON inverter, (2) inductors, (3) xPCTarget system, (4) xPCTarget host, (5) Photovoltaic simulator, (6) oscilloscope.

Table 3. Prototype values

\begin{tabular}{lc}
\hline Parameter & Value \\
\hline Filter inductance L1 (ferromagnetic core) & $13 \mathrm{mH} \times 2$ \\
\hline Filter inductance L2 (air core) & $5.5 \mathrm{mH} \times 2$ \\
\hline HSFI Switching frequency & $10 \mathrm{kHz}$ \\
\hline
\end{tabular}

The proposed PIS behaves as in the simulation setup. The supply current is a high quality sinusoidal wave in phase with the source voltage so attaining a unity power factor. One can notice that the total current is obtained principally by the QSWI and corrected by the HSFI operation. The HSFI current has a lower RMS value than the QSWI current. The QSWI operates with an angle of about 60 degrees (Fig 17 - channel 2).

\section{CONCLUSION}

In this paper a new topology for the power injection system used in photovoltaic generation systems is presented. This topology is based on the cooperative parallel association of two inverters, one operating at a low switching frequency (equal to the grid frequency) and the other at a standard switching frequency (above $10 \mathrm{kHz}$ ). The performance of the proposed system was tested by simulation and by a simple laboratory prototype. The proposed system optimizes the system design, permitting the reduction of the system losses (conduction and switching losses, and Joule effect losses in inductors) and so increases the energy effectively injected into the grid. There will consequently be an increase in profit when selling this energy.

We also showed how a simple PI controller can be used as the basis for the MPPT algorithm. Furthermore we demonstrated how the power stage of the PIS can work without a DC/DC converter and can be operated by only controlling the current injected into the grid. Finally, we showed how the overall performance can be improved (guaranteeing maximum energy extraction) with a PI controller that operates to reduce the error between the reference and the measured PVGS current. 


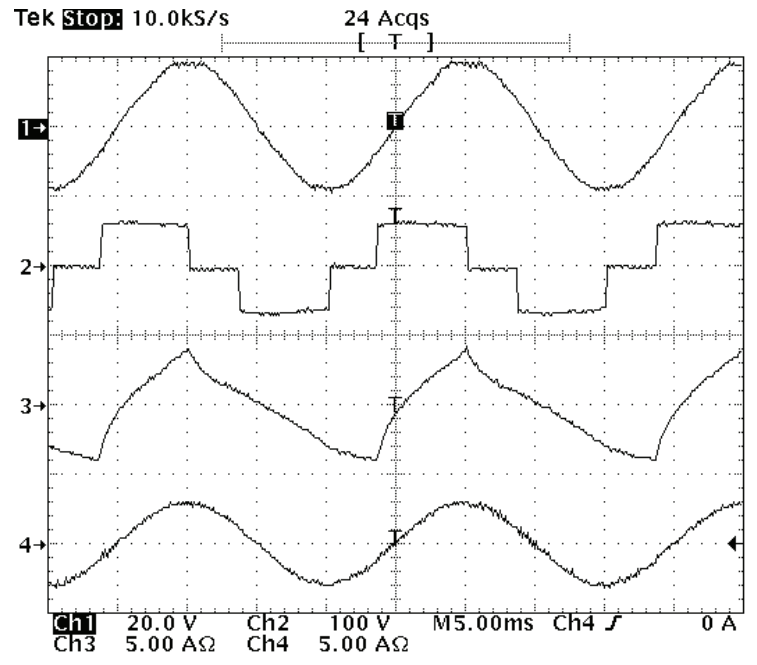

Fig. 17 Experimental waveforms: (a) Grid voltage, (b) QSWI voltage, (c) QSWI current, and (d) supply current.

The resulting control system complexity is not excessive, because it could be said that the QSWI is operated in a quasi-open-loop and the current controller used in the HSFI is a synchronous hysteresis controller.

The most complex component is synchronization module that was not considered in this paper because a detailed description of the used synchronization module was given in [8].

This paper's results could be improved by substituting the hysteresis current controller used in the HSFI for another kind of high switching frequency current controller (for example, dead-beat current controller [9]) but it would result in a more complex control algorithm.

The authors are working at present on building a higher rating PIS prototype and evaluating the possibility to use high power semiconductors (like GTOs [13]) in the QSWI.

\section{REFERENCES}

[1] Carrasco, J.M.; Franquelo, L.G.; Bialasiewicz, J.T.; Galvan, E.; Portillo-Guisado, R.C.; Prats, M.A.M.; Leon, J.I.; Moreno-Alfonso, N. "Power-Electronic Systems for the Grid Integration of Renewable Energy Sources: A Survey". IEEE Transactions on Industrial Electronics, vol. 53, issue 4, pages:1002 - 1016. June 2006.

[2] Weidong Xiao; Ozog, N.; Dunford, W.G. "Topology Study of Photovoltaic Interface for Maximum Power Point Tracking”. IEEE Transactions on Industrial Electronics, vol 54, issue 3, pages 1696 - 1704. June 2007.

[3] Kwon, J.-M.; Nam, K.-H.; Kwon, B.-H., "Photovoltaic Power Conditioning System With Line Connection". IEEE Transactions on Industrial Electronics, vol. 53, issue 4, pages 1048- 1054. June 2006.

[4] Gupta, A.K.; Khambadkone, A.M. "A Space Vector PWM Scheme for Multilevel Inverters Based on Two-Level Space Vector PWM". IEEE Transactions on Industrial Electronics, vol. 53, issue 5, pages 1631 - 1639. October 2006.

[5] Tekwani, P. N.; Kanchan, R. S.; Gopakumar, K. "Novel Current Error Space Phasor Based Hysteresis Controller Using Parabolic Bands for Control of Switching Frequency Variations". IEEE Transactions on Industrial Electronics, vol. 54, issue 5, pages 2648 - 2656. October 2007

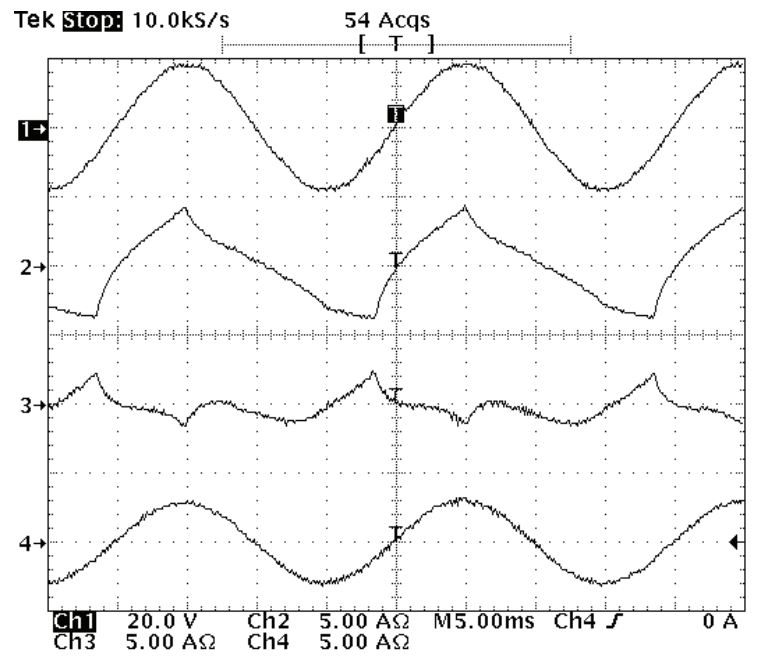

Fig. 18 Experimental waveforms: (a) Grid voltage, (b) QSWI current, (c) HSFI current, and (d) total injected current.

[6] Baumann, M.; Kolar, J. W. "Parallel Connection of Two Three-Phase Three-Switch Buck-Type Unity-Power-Factor Rectifier Systems With DC-Link Current Balancing”. IEEE Transactions on Industrial Electronics, vol. 54, issue 6, pages 3042 - 3053. December 2007.

[7] Bor-Jehng Kang; Chang-Ming Liaw. "A robust hysteresis current-controlled PWM inverter for linear PMSM driven magnetic suspended positioning system". ". IEEE Transactions on Industrial Electronics, vol. 48, issue 5, pages 956 - 967. October 2001.

[8] Milanes-Montero, M. I.; Romero-Cadaval, E.; de Marcos, A. Rico; Minambres-Marcos, V. M.; Barrero-Gonzalez, F. "Novel method for synchronization to disturbed threephase and single-phase systems". IEEE International Symposium on Industrial Electronics, 2007. ISIE 2007, pages 860 - 865. 4-7 June 2007

[9] Allmeling, J. "A control structure for fast harmonics compensation in active filters". IEEE Transactions on Power Electronics, vol 19, issue 2, pages 508 - 514. March 2004

[10] Moreno, V. M.; Liserre, M.; Pigazo, A.; Dell'Aquila, A. “A Comparative Analysis of Real-Time Algorithms for Power Signal Decomposition in Multiple Synchronous Reference Frames". IEEE Transactions on Power Electronics, vol 22, issue 4, pages 1280 - 1289. July 2007 -

[11] Montero, M. I. M.; Cadaval, E. R.; Gonzalez, F. B "Comparison of Control Strategies for Shunt Active Power Filters in Three-Phase Four-Wire Systems". IEEE Transactions on Power Electronics, vol. 22, issue 1, pages 229-236. January. 2007.

[12] Rico, Amparo; Cadaval, Enrique Romero; Montero, Maria Isabel Milanes. "Power Injection Control System and Experimental Model based on Manufacturer Characteristic Curves for a Photovoltaic Generation System". Compatibility in Power Electronics, 2007. CPE '07, pages 1 - 7. May 29 2007-June 12007.

[13] Dixon, J.; del Valle, Y.; Orchard, M.; Ortuzar, M.; Moran, L.; Maffrand, C. "A Full Compensating System for General Loads, Based on a Combination of Thyristor Binary Compensator and a PWM-IGBT Active Power Filter", IEEE Trans. Industrial Electronics, vol. 50, issue 5, pages 982-989. October 2003.

[14] Barrero, F.; Martinez, S.; Yeves, F.; Martinez, P.M. "Active power filters for line conditioning: a critical evaluation", IEEE Trans. on Power Delivery, vol. 15, issue 1, pages 319-325. January 2000. 


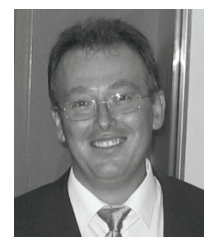

Enrique Romero-Cadaval (S'03-M'05) was born in Villafranca de los Barros, Badajoz, Spain, in 1968. He received the M.Sc. degree in electronic industrial engineering from ICAI, Universidad Pontificia de Comillas, Madrid, Spain, in 1992 and the $\mathrm{Ph}$. D. degree from the Universidad de Extremadura, Badajoz, Spain, in 2004. He is a full Professor in power electronics at the Universidad

de Extremadura, Badajoz, Spain. He is currently with the Power Electrical and Electronic Systems (PE\&ES) Research Group (http://peandes.unex.es). His research interests are power electronics in the power system, power quality, electromagnetic interferences, active power filters, and renewable energy sources control.

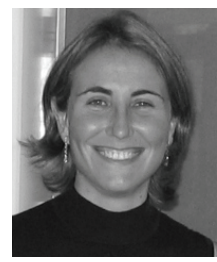

María Isabel Milanés-Montero (S'03-M'06) was born in Badajoz, Spain, in 1974. She received the M.Sc. degree in industrial engineering from the Universidad de Extremadura, Badajoz, Spain, in 1997 and the $\mathrm{Ph}$. D. degree from the Universidad de Extremadura, Badajoz, Spain, in 2005. In November 1998 she joined the Electrical, Electronics and Automation Engineering Department, Universidad de Extremadura, as an Assistant Professor. She is currently with the Power Electrical and Electronic Systems (PE\&ES) Research Group (http://peandes.unex.es). Her major fields of interest include solid-state power converter design and control, electromagnetic interferences, power quality, renewable energy sources control, and electrical machine drives.

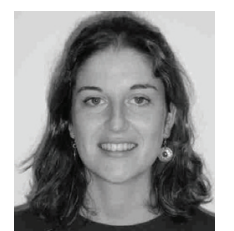

Eva González-Romera (S'05-M'06) received the Industrial Engineering degree and the $\mathrm{Ph} . \mathrm{D}$. degree from the University of Extremadura, Badajoz, Spain, in 1998 and 2005, respectively. Currently, she is an Assistant Professor with the Department of Electrical, Electronics and Automation Engineering, University of Extremadura, Badajoz, Spain. Her primary areas of interest are power quality and load forecasting.

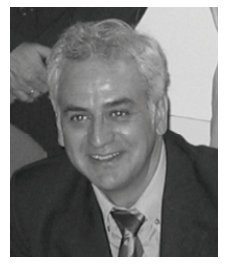

Fermín Barrero-González (M'95) was born in Puebla de la Reina, Badajoz, Spain, in 1959. He received the M.Sc. degree in electrical engineering from the Universidad Politécnica de Madrid in 1984 and the Ph.D. degree from the Universidad Nacional de Educación a Distancia in 1995. He is a full Professor in electrical engineering at the Universidad de Extremadura, Spain. He is currently coordinating the Power Electrical and Electronic Systems (PE\&ES) Research Group (http://peandes.unex.es). His research interest areas are power electronics in the power system, FACTS, active power filters, and electrical machine drives. Dr. Barrero is a member of the IEEE IAS Industrial Static Converters Committee, European Working Group. 